\title{
Tuberculosis in London: a decade and a half of no decline
}

\author{
Sarah R Anderson, Helen Maguire, Jacqui Carless
}

Thorax 2007;62:162-167. doi: 10.1136/thx.2006.058313

\begin{abstract}
See end of article for authors' affiliations

......................

Correspondence to: Dr S R Anderson, North West London Health Protection Unit, 61 Colindale Avenue, London NW9 5EQ, UK; sarah.anderson@ hpa.org.uk
\end{abstract}

Received 3 January 2006 Accepted 5 October 2006 Published Online First 13 November 2006

\begin{abstract}
Background: London accounts for nearly half of the national burden of tuberculosis. The incidence of tuberculosis has more than doubled in London in the past 15 years.

Methods: Data from the enhanced tuberculosis surveillance 1999-2003, the national tuberculosis surveys of 1993 and 1998, and tuberculosis notifications were compared and analysed.

Results: In 2003, 3048 patients with tuberculosis were reported in London, $45 \%$ of the national total. This represents an incidence of 41.3/100 000, five times higher than the rest of England and Wales, and in parts of London the incidence of tuberculosis is nine times the national average. $75 \%$ of people with tuberculosis in London are born abroad; nearly half have lived in the UK for $<5$ years, but a third for $>10$ years. $86 \%$ are from an ethnic minority group, and the incidence is highest in black Africans at 283/100 000 compared with 141,141 and 8/100 000 for Pakistanis, Indians and whites, respectively. In absolute terms, a third of patients with tuberculosis in London are from Africa and nearly a third from the Indian subcontinent. Specific groups affected also include the homeless, prisoners, and hard drug and alcohol users as well as the immunosuppressed.

Conclusions: London reflects the worldwide rise in tuberculosis, with increasing incidence in ethnic minorities. Work has been carried out to combat this rise, but more is needed. Tuberculosis control and prevention strategies should be mindful of the changing epidemiology of tuberculosis in London, and provide information, diagnosis and treatment tailored to the specific needs of the capital and its at-risk groups.
\end{abstract}

$\mathrm{T}$ uberculosis is increasing across the UK and is a particular public health concern in London. In England and Wales, the incidence of tuberculosis declined throughout most of the 20th century. ${ }^{1}$ However, since the mid-1980s this trend has reversed. ${ }^{2}$ Contributing to the rise are changing patterns of immigration, ${ }^{3-6}$ increased homelessness ${ }^{3-11}$ and HIV infection, $^{39}$ as well as an ageing population. More than $40 \%$ of patients with tuberculosis in England and Wales live in London. ${ }^{2}$ Research published in the past few years showed that the incidence of tuberculosis in London is especially high in recently arrived immigrants, ${ }^{2}{ }^{12}$ and varies significantly by borough. ${ }^{13}$ This paper provides a summary of the changing epidemiology of tuberculosis in London over the past decade and a half.

\section{METHODS}

London data from the enhanced tuberculosis surveillance (ETS) 1999-2003, the national tuberculosis surveys of $1993^{14}$ and $1998,{ }^{2}$ and tuberculosis notifications were compared and analysed. Since 2002, surveillance in London has been possible through the Health Protection Agency London Tuberculosis Register (LTBR), which is a web-based system used in every tuberculosis clinic across the city. Validation of these data is ongoing at both regional and national levels, and methods for the 1993 and 1998 national tuberculosis surveys have been described elsewhere. ${ }^{214}$ Estimates of population denominator data were obtained from the 1991 and 2001 census. Geographic information systems were used to plot cases by postcode and borough.

\section{RESULTS}

\section{Cases, age and sex}

In 2003, London accounted for $45 \%$ of the national tuberculosis burden; 3048 cases of tuberculosis were reported via ETS (the LTBR). This represents an incidence of 41.3/100 000, five times higher than the rest of England and Wales at 8.2/100 000. Over the past 15 years, tuberculosis notifications have doubled in London from just over 20/100 000 in 1987, but have remained fairly constant in the rest of England and Wales (fig 1).

The age distribution of new cases of tuberculosis in London has changed over the past 7 years (fig 2). Tuberculosis notifications rose most rapidly in the $25-34$-year-old age group and remain highest in this group. In 2003, the incidence of tuberculosis in 25-34-year-old men was 60/100 000 and in women 52/100 000 (fig 3). Since 2001, rates have fallen slightly in those $>45$ years.

\section{Geographical distribution}

Tuberculosis is concentrated in particular areas of London. In 2003, of 33 London boroughs, 14 (one third) had an incidence of tuberculosis >40/100 000; these "hot spots" are not exclusively inner-city districts but also include suburban areas with well-established ethnic communities. Hot spots have not changed much over the time period of our review (fig 4).

In 2003, Newham, Hackney and Brent had the highest formal notification rates $(96.4,91.8$ and $64.2 / 100000$ population, respectively). However, there has been a decrease from a high in 2001 of 116/100 000 in Newham (northeast London) and 103 in Brent (northwest London). Since 1987, tuberculosis rates have risen fivefold in Hillingdon (west) and Sutton (southwest), fourfold in Greenwich (southeast) and threefold in Enfield (north), Hackney, Barking and Dagenham (northeast).

\section{Ethnicity and country of birth}

In $2003,86 \%$ of tuberculosis cases in London were from a nonwhite ethnic group, 35\% were black African and 31\% were from the Indian subcontinent. Between 1999 and 2003, the proportion of tuberculosis notifications in the white population fell,

Abbreviations: ETS, enhanced tuberculosis surveillance; LTBR, London Tuberculosis Register; NYC, New York city 


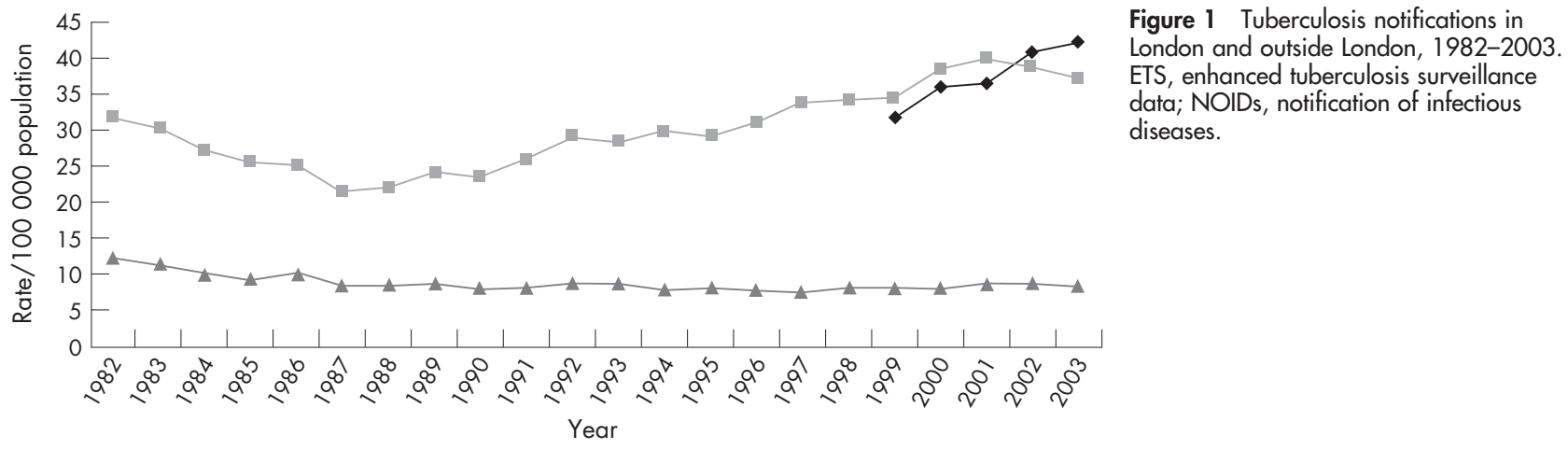

政 London and outside London, 1982-2003. ata; NOIDs, notification of infectious

- London ETS —- London NOIDs —- Rest of England and Wales NOIDs

but rose in nearly all other ethnic groups. In the past 5 years, tuberculosis in black African communities has risen markedly. In 2003, the tuberculosis incidence in black Africans was 283/ 100000 compared with 141, 141 and 8/100 000 for Pakistanis, Indians and whites, respectively (fig 5). The incidence in black Africans aged 25-44 years was 407/100 000 compared with 41/ 100000 for all ages and ethnic groups across London, and 8.2/ 100000 across the rest of England and Wales. In black Africans, tuberculosis is found more commonly in new entrants and those who have lived in the UK for $<5$ years.

ETS data from the LTBR show that most of the patients with tuberculosis in the white population are aged $>45$ years, whereas in black African communities, most patients are aged 25-44 years and in the community from the Indian subcontinent, there is a mix of middle and old-aged people (fig 6).

The vast majority of patients with tuberculosis in London are born abroad (fig 7). In 2003, 75\% were born abroad (where place of birth was known). This percentage has risen steadily, from 55\% since 1993. In the past 10 years, India has remained the most commonly reported country of birth for patients born abroad. The other top 10 countries have remained similar, apart from a substantial rise in Somalian patients between 1993 and 1998, and a rise in Afghan patients since 1999.

In $2003,46 \%$ of patients with tuberculosis born abroad had entered the UK in the past 5 years and $27 \%$ had lived in the UK for $>10$ years. On further analysis of those born abroad in the two largest ethnic minority subgroups, black Africans were more likely to be new entrants or residents in the UK for

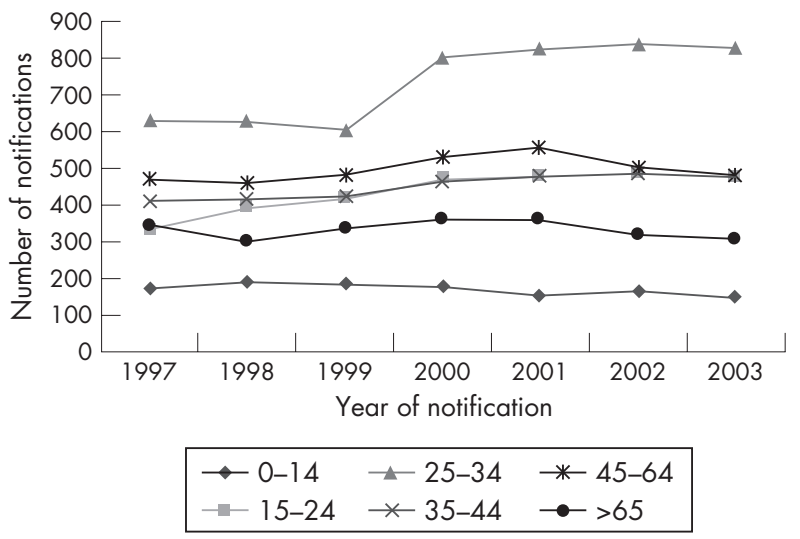

Figure 2 Tuberculosis notifications in London by age group, 1997-2003.
$<5$ years $(52 \%)$, whereas patients with tuberculosis from the Indian subcontinent were more likely to have lived in the UK for $>10$ years (fig 8 ).

\section{Tuberculosis and HIV}

Coinfection with tuberculosis and HIV is an increasing problem in London (table 1). In 1993, 3.3\% of patients with tuberculosis were coinfected; by 1998 , this had risen to $5.4 \%{ }^{15}$ and by 2001 the rate was $6.5 \%$ (V Delpech, HPA Colindale, personal communication, 2005). This is thought to be an underestimate. Reports from London hospitals suggest that rates of coinfection are as high as $17-25 \%{ }^{16}{ }^{17}$ It has been estimated that about three quarters of the national population coinfected with HIV and tuberculosis live in London, most of whom are black African. ${ }^{15}$ Between 1993 and 1998, coinfection increased by a factor of 2.5 in black Africans and by a factor of 0.6 in whites. ${ }^{15}$ It was estimated that between 1993 and 1998, 11\% of the rise in London's tuberculosis cases could be attributed to HIV. ${ }^{15}$ It is important to offer and recommend HIV testing for all patients with tuberculosis in London so that both infections can be properly treated.

\section{Drug-resistant tuberculosis}

Both isoniazid-resistant and multidrug-resistant tuberculosis are bigger problems in London than elsewhere in England and Wales. In 2003, 9.4\% of isolates were isoniazid resistant in London (fig 9) compared with 7.5\% nationally. Rates of isoniazid-resistant tuberculosis were relatively stable until 2000, but have risen slightly since then mainly because of a large outbreak of isoniazid-monoresistant tuberculosis. ${ }^{18}$ Over

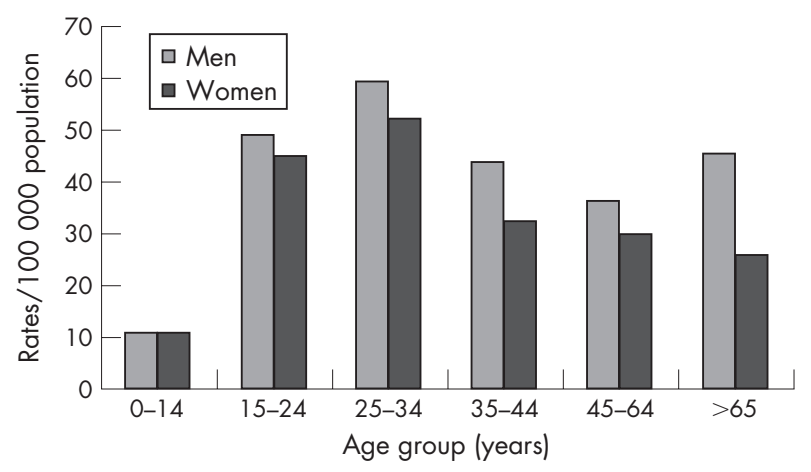

Figure 3 Tuberculosis notification rates in London by age and sex in 2003. 


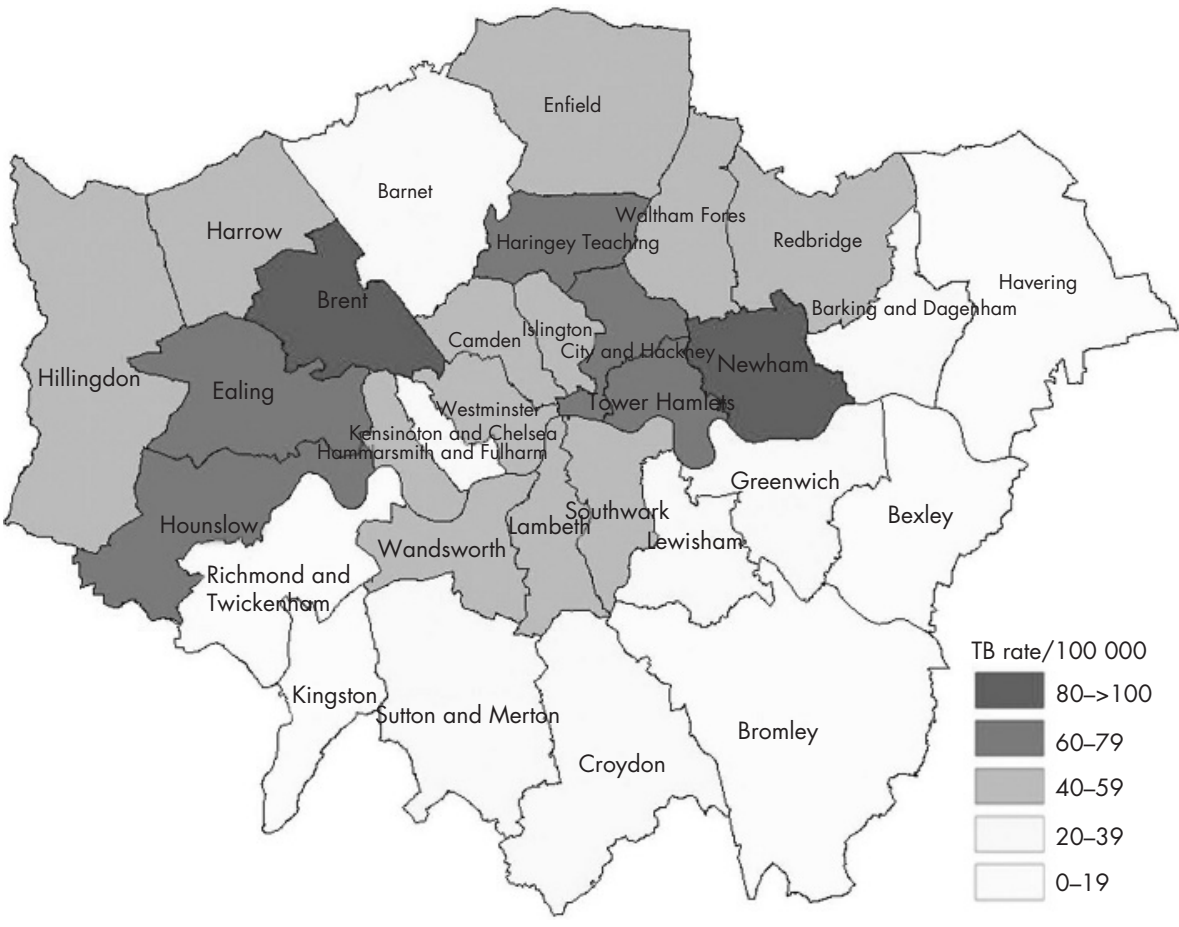

Figure 4 Geographical distribution of patients with tuberculosis in London, 2003. the past 5 years, rates of multidrug-resistant tuberculosis have been about $1-1.5 \%$ in London, with just a slight rise to $2 \%$ in 2003 (the most recent year for which data are available).

\section{Outcome of treatment}

In 2003, treatment outcome data were available through the LTBR. Patients notified during 2002 were followed-up 1 year after starting treatment. In all, $82 \%$ had completed a full course of treatment, $10 \%$ had not completed treatment and $8 \%$ were either lost to follow-up or had an unknown outcome. Of the $10 \%$ not completing treatment, two thirds had died and for just under half of these tuberculosis had caused or contributed to death.

\section{Molecular epidemiology of tuberculosis}

Research published in 2002 using molecular typing showed that tuberculosis in London was mainly caused by reactivation or importation of infection by recent immigrants. ${ }^{19}$ New infections were common in people with recognised risk factors such as alcoholism or HIV. The main findings were the importance of preventive interventions and early diagnosis in immigrants, along with thorough contact tracing and monitoring of treatment outcome in groups at higher risk of new infection. This molecular study was conducted in the late 1990s before a large outbreak of drug-resistant tuberculosis in north London; its findings may now have changed. The outbreak has emphasised the vulnerability of groups such as drug users and prisoners in London to recent new infection. ${ }^{18}$

\section{Risk groups}

A cross-sectional survey performed in London in July 2003 found the overall prevalence of tuberculosis to be 27/100 000, but reached 788 in people sleeping rough or using direct-access homeless hostels, 550 in prisoners, 172 in drug users and 878 in patients diagnosed HIV positive. This survey showed a prevalence of disease of 149/100 000 in recent migrants and of 92/100 000 among refugees and asylum seekers. ${ }^{20}$

\section{DISCUSSION}

Tuberculosis is an increasing problem in London. Over the past 15 years, its incidence has doubled to 41.3/100 000 and continues to rise. In 2003, 3048 cases were reported via the

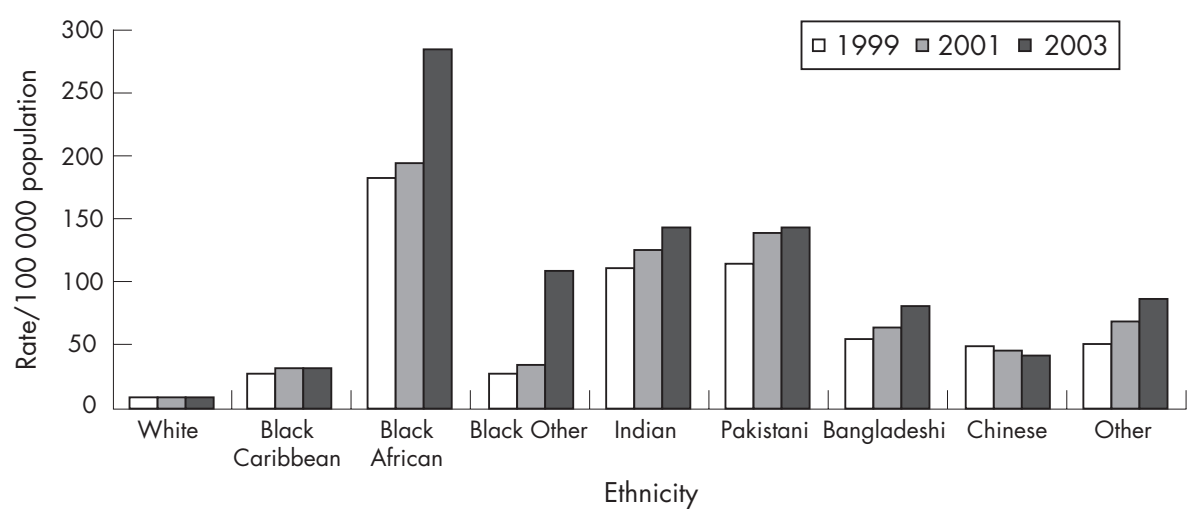

Figure 5 London tuberculosis notification rates by ethnic group: 1999, 2001 and 2003. 


\begin{tabular}{lll} 
Table 1 & Tuberculosis/HIV coinfection \\
\hline & 1993 & 1998 \\
\hline London & $3.3 \%(39)$ & $5.4 \%(86)$ \\
England and Wales & $2.2 \%(61)$ & $3.3 \%(112)$ \\
\hline Source: Rose et al ${ }^{5}$ & & \\
\hline
\end{tabular}

ETS, $45 \%$ of the national total. A discrepancy exists between statutory notifications and LTBR data, as fig 1 shows. In 2003, 2745 patients with tuberculosis were formally notified in London compared with 3048 notified via the LTBR. The ETS is likely to better reflect the true incidence of tuberculosis as it undergoes more rigorous validation than statutory notifications. Caution has been advised in the interpretation of statutory notification data. ${ }^{21}$

The incidence of tuberculosis varies substantially between different ethnic groups. In 2003, 86\% of patients with tuberculosis in London were from an ethnic minority, a reflection of the effect of the global epidemic of tuberculosis. ${ }^{22}$ Three quarters of patients were born abroad, in countries where the incidence of tuberculosis is much higher. The importance of this for prevention and control is that primary care or community services need to be increasingly aware of at-risk groups, and target case finding and treatment appropriately. We have shown that incidence varies across London boroughs from $<10 / 100000$ to $96 / 100000$ (nearly 10 times the national average) and in recent years London's tuberculosis hot spots have remained largely unchanged, although a few areas have seen increases of up to fivefold. The hot spots are not exclusively inner-city districts but also include suburban areas with well-established ethnic communities. Immigration patterns to the UK have changed over time, ${ }^{6}$ with more people arriving from the Indian subcontinent $>10$ years ago and young Africans more recently. Africans made up $41 \%$ of all asylum applications in 2003 and Asians 27\%. ${ }^{23}$ Our results reflect the changing patterns of immigration (with higher rates of tuberculosis in older Asians with longer residency and younger more recently arrived Africans) and highlight the fact that it is not just recently arrived immigrants who are developing tuberculosis. Tuberculosis control and prevention strategies need to be mindful of this, and provide information, diagnosis and treatment to newly arrived immigrants, as well as for more established ethnic communities.

According to 2001 census data, about seven million people live in London. From 1991 to 2001, the proportion of people from an ethnic minority increased from $20 \%$ to $29 \%$. The increase was evident in all ethnic minority groups, with the greatest increase seen for black Africans, a doubling from $2.4 \%$ to $5.4 \%$. As a reflection of this, tuberculosis in black African communities has risen markedly in the past 5 years. The current notification rate for all ages is 283/100 000 and for the 25-44-year age group 407/100 000. In black Africans, tuberculosis is found more commonly in new entrants and in those who have lived in the UK for $<5$ years. This suggests that a greater understanding of this group is needed, and more resources to assess and diagnose newly arrived black Africans in addition to further prevention work.

The rise in tuberculosis notification in London is likely to have many causes. Apart from the changing patterns of immigration, other factors that affect tuberculosis epidemiology include: increased detection through increased staff-to-patient ratios and heightened awareness of tuberculosis in both the public and healthcare staff; increased opportunities for international travel with exposure to tuberculosis in countries with a high incidence; HIV infection in London at an all time high; and the emergence of drug-resistant tuberculosis-rising

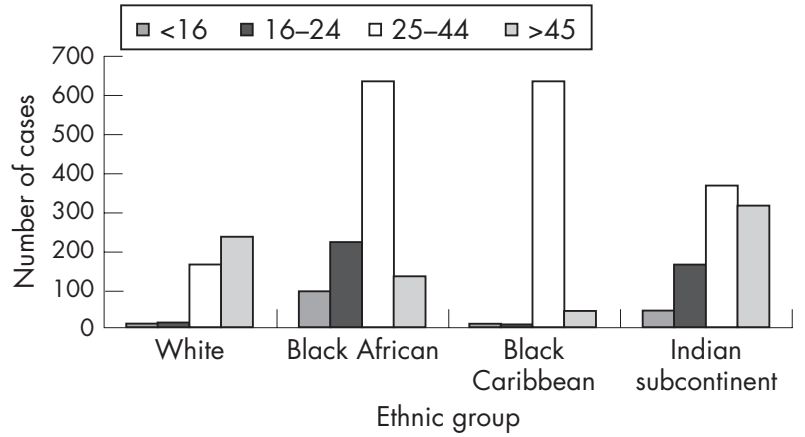

Figure 6 Number of patients with tuberculosis in London by age and ethnic group, 2003.

slowly, and mainly because of a large outbreak of isoniazidmonoresistant tuberculosis. ${ }^{18}$ In addition, incidence and prevalence rates of tuberculosis are documented to be high in the homeless ${ }^{811}$ and in prison populations, ${ }^{18}{ }^{20}$ groups that are often marginalised and difficult to reach and engage. ${ }^{24}$

\section{Can we learn from the New York experience?}

In the early 1990s, tuberculosis had reached epidemic proportions in New York City (NYC). This epidemic differed in several ways from that in London; London has a much higher proportion of immigrants infected with tuberculosis (London, $80 \% \vee$ NYC, $25 \%$ ), a much lower proportion of patients with tuberculosis coinfected with HIV (London, 6.5\% v NYC, 38\%) and lower levels of multidrug-resistant tuberculosis (London, $1.2 \% v$ NYC, $19 \%) .{ }^{25}$ However, there are similarities between the two epidemics, such as similar numbers of cases at the epidemic peak and a higher prevalence in lower socioeconomic classes, ethnic minorities and the homeless. The epidemic in NYC was brought under control by broadening treatment regimens, using directly observed treatment and structured guidelines for control and prevention. ${ }^{26}$ The reduction in patients in NYC has largely been confined to those born in the US. ${ }^{27}$ As tuberculosis in London is mostly found in non-UK born ethnic minorities, all the lessons learnt in New York may not be appropriate. However, New York had a sub-epidemic of drug resistant tuberculosis and the lessons learnt from its containment might be helpful for London. Similarly, for patients with tuberculosis coinfected with HIV, London might benefit from reviewing New York's policies, as the fastest growing group of patients with tuberculosis are 25-34-year-old black Africans who also have the highest rates of coinfection.

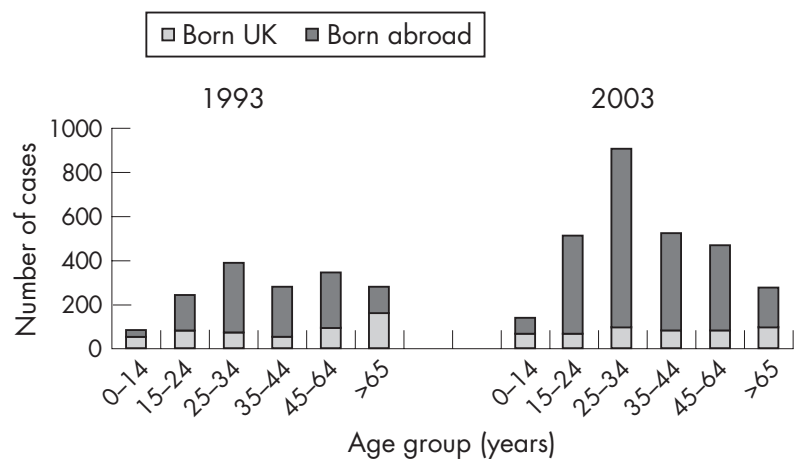

Figure 7 Number of patients with tuberculosis born in the UK and abroad in 1993 and 2003 by age group 


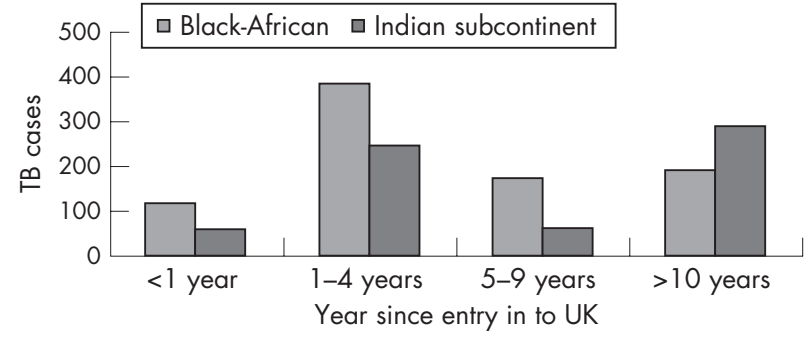

Figure 8 Years since entry into the UK for patients with tuberculosis (TB) from Africa and the Indian subcontinent

\section{What does all this mean for London?}

Tuberculosis in London is an increasing public health concern, but there have been some service improvements reported in each of London's five sectors together with the creation of multidisciplinary tuberculosis networks. Service improvements include greater monitoring of treatment completion, an increase in the number of tuberculosis nurses and the use, since 2002, of the Health Protection Agency LTBR in all tuberculosis clinics. The LTBR is a web-based electronic case management and surveillance system that allows patients to be tracked as they move between clinics, and thereby improves local service monitoring of patient outcomes. A mobile screening project using targeted digital radiography is being piloted in London to evaluate how this approach could strengthen the screening of defined populations, including for example prisoners or hostel dwellers.

Further improvements are possible, and these include: improved case finding in high-risk groups by screening those known to be at particular risk-for example, residents of hostels for refugees, asylum seekers or the homeless ${ }^{11}{ }^{28}$; early detection in new entrants and better access to primary care services $^{128-30}$; early recognition of symptoms by doctors and patients; a continuing emphasis on treatment continuity and completion, with the use of directly observed therapy where appropriate to help reduce drug resistance ${ }^{26} 31$; better diagnosis of tuberculosis/HIV coinfection to enable treatment of both conditions appropriately ${ }^{32}{ }^{33}$; and an increased awareness of the social dimensions of tuberculosis control so that health services work more closely with other agencies. ${ }^{26} 2934$

The Chief Medical Officer's tuberculosis action plan ${ }^{35}$ published in October 2004 provides a framework to assist tuberculosis prevention and control, and builds on the existing structures and multidisciplinary working across London's tuberculosis networks. The National Institute for Health and Clinical Excellence has recently issued clinical diagnosis and management guidelines for tuberculosis. ${ }^{28}$ These guidelines make recommendations on good practice and attempt to focus National Health Service resources where they will most effectively combat the spread of tuberculosis.

\section{CONCLUSION}

The global rise in tuberculosis continues, and tuberculosis in London reflects this with increasing rates in ethnic minorities. Drug resistance and coinfection with HIV are growing problems. Control of tuberculosis in London needs to improve, and ultimately treatment and control services should be tailored to the specific needs of the capital and its at-risk groups. This is the time to apply the full weight of political, organisational and individual will to tackle London's tuberculosis problem.

\section{ACKNOWLEDGEMENTS}

We thank the London community tuberculosis teams, NHS staff at tuberculosis clinics and HPA colleagues across London and at the Mycobacterium Reference Unit.

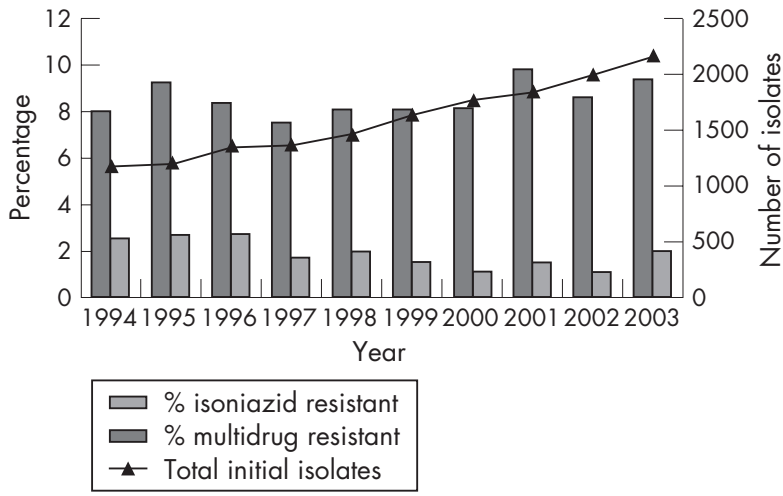

Figure 9 Tuberculosis drug resistance in London, 1994-2003. Source: Health protection agency Mycobacterial Resistance Network (MycobNet).

\section{Authors' affiliations}

Sarah R Anderson, North West London Health Protection Unit, London, UK Helen Maguire, Health Protection Agency, London, UK Jacqui Carless, Health Protection Agency, London, UK

Competing interests: None.

\section{REFERENCES}

1 Watson JM, Maguire H. PHLS work on the surveillance and epidemiology of tuberculosis. Commun Dis Rep 1997:7:R110-12.

2 Rose AM, Watson JM, Graham C, et al. Tuberculosis at the end of the 20th century in England and Wales: results of a national survey in 1998. Thorax 2001;56:173-9.

3 Watson JM. Tuberculosis in Britain today [editorial]. BMJ 1993;306:221-2.

4 Coker R. Compulsory screening of immigrants for tuberculosis and HIV. BMJ 2004;328:298-300.

5 Callister MEJ, Barringer J, Thanabalasingam ST, et al. Pulmonary tuberculosis among political asylum seekers screened at Heathrow Airport, London, 1995-9. Thorax 2002:57:152-6.

6 Home Office. Control of Immigration: statistics United Kingdom. Home Office Statistical Bulletin HOSB 12/04, 2003. http://www.homeoffice.gov.uk/rds/ pdfs04/hosb1204.pdf (accessed 17 Nov 2006).

7 Ormerod LP, Shaw RJ, Mitchell DM. Tuberculosis in the UK, 1994: current issues and future trends [editorial]. Thorax 1994:49:1085-9.

8 Kumar D, Citron KM, Leese J, et al. Tuberculosis among the homeless at a temporary shelter in London: a report of chest X-ray screening programme. $J$ Epidemiol Community Health 1995;49:629-33.

9 Joint Tuberculosis Committee of the British Thoracic Society. Control and prevention of tuberculosis in the United Kingdom: code of practice 2000. Thorax 2000;55:887-901.

10 The Interdepartmental Working Group on Tuberculosis. The prevention and control of tuberculosis in the United Kingdom: tuberculosis and homeless people. London: Department of Health and the Welsh Office, 1996.

11 Southern A, Premaratne N, English M, et al. Tuberculosis among homeless people in London: an effective model of screening and treatment. Int J Tuberc Lung Dis 1999;3:1001-8.

12 Bothamley GH, Rowan JP, Griffiths CJ, et al. Screening for tuberculosis: the port of arrival scheme compared with screening in general practice and the homeless. Thorax 2002;57:45-9.

13 Melzer M, Storring RA, Bagg LR. Tuberculosis in an area bordering east London: significant local variation when compared to national data. Infection 2000;28:103-5.

14 Kumar D, Watson JM, Charlett A, et al. Tuberculosis in England and Wales in 1993: results of a national survey. Thorax 1997;52:1060-7.

15 Rose AM, Sinka K, Watson JM, et al. An estimate of the contribution of HIV infection to the recent rise in tuberculosis in England and Wales. Thorax 2002;57:442-5.

16 Marshall B, Mitchell D, Shaw R, et al. HIV and tuberculosis co-infection in an inner London hospital: a prospective anonymised seroprevalence study. J Infect 1999;38:162-6.

17 Bowen E, Rice P, Cooke N, et al. HIV seroprevalence by anonymous testing in patients with Mycobacterium tuberculosis and in tuberculosis contacts. Lancet 2000;356:1488-9

18 Ruddy MC, Davies AP, Yates MD, et al. Outbreak of isoniazid resistant tuberculosis in north London. Thorax 2004;59:279-85.

19 Maguire H, Dale J, McHugh T, et al. Molecular epidemiology of tuberculosis in London 1995-7 showing low rate of active transmission. Thorax 2002;57:617-22.

20 Story A, Roberts W, Hayward A, et al. Tuberculosis in London. Int J Tuberc Lung Dis 2004;8(suppl 1):S197-S198.

21 HPA. Statutory notification of tuberculosis [News]. Commun Dis Rep Wkly [serial online], 2004; 14.http://www.hpa.org.uk/cdr/archives/2004/cdr3004.pdf (accessed 17 Nov 2006). 
22 Dye C. Global epidemiology of tuberculosis Lancet 2006:367:938-40.

23 Home Office. Asylum statistics United Kingdom 2003. Home Office Statistical Bulletin HOSB 11/04, 2003 http://www.homeoffice.gov.uk/rds/pdfs04/ hosb1 104.pdf (accessed 17 Nov 2006).

24 Story A, Van Hest R, Hayward A. Tuberculosis and social exclusion. BM 2006;333:57-8.

25 Hayward AC, Coker RJ. Could a tuberculosis epidemic occur in London as it did in New York? Emerg Infect Dis 2000;6:12-16.

26 Paolo WF, Nosanchuk JD. Tuberculosis in New York City: recent lessons and a look ahead. Lancet Infect Dis 2004:4:287-93.

27 Geng E, Kreiswirth B, Driver C, et al. Changes in transmission of tuberculosis in New York City from 1990 to 1999. N Engl J Med 2002;346:1453-8.

28 National Institute for Health and Clinical Excellence (NICE). Tuberculosis Clinical diagnosis and management of TB and measures for its prevention and control. CG33 Tuberculosis full guideline, 2006. http://www.nice.org.uk/ page. aspx?o=297929 (accessed 17 Nov 2006)
29 Van den Bosch CA Roberts JA. Tuberculosis screening of new entrants; how can it be made more effective? J Public Health 2000;22:220-3

30 Verver S, Bwire R, Borgdorff MW. Screening for pulmonary tuberculosis among immigrants: estimated effect on severity of disease and duration of infectiousness. Int J Tuberc Lung Dis 2001;5:419-25.

31 Davies PD. The role of DOTS in tuberculosis treatment and control. Am J Respir Med 2003;2:203-9.

32 Fujiwara PI, Clevenbergh P, Dlodlo RA. Management of adults living with HIV/ AIDS in low-income, high-burden settings, with special reference to persons with tuberculosis. Int J Tuberc Lung Dis 2005:9:946-58.

33 Day JH, Grant AD, Fielding KL, et al. Does tuberculosis increase HIV load? J Infect Dis 2004; 190:1677-84.

34 Schluger NW, Huberman R, Wolinsky N, et al. Tuberculosis infection and disease among persons seeking social services in New York City. Int J Tuberc Lung Dis 1997;1:31-7.

35 Department of Health. Stopping tuberculosis in England: an action plan from the Chief Medical Officer. London: Department of Health, 2004.

\section{LUNG ALERT}

Treatment of latent tuberculosis with rifampicin is associated with higher completion rates

$\Delta$ Page KR, Sifakis F, Montes de Oca R, et al. Improved adherence and less toxicity with rifampicin vs. isoniazid for treatment of latent tuberculosis. Arch Intern Med 2006;166:1863-70.

$\mathrm{n}$ this retrospective study, medical records of 2255 patients who received treatment for latent

tuberculosis infection (LTBI) at a US centre between January 1999 and January 2004 were reviewed. Adherence to LTBI treatment was compared between two groups of patients. One group (843 patients) received isoniazid for 9 months and the other (1412 patients) received rifampicin for 4 months.

In the isoniazid group $52.6 \%$ of patients completed $80 \%$ or more of the LTBI treatment, compared with $71.6 \%$ of the rifampicin group $(\mathrm{p}<0.001)$. However, similar percentages of people completed 4 months' of treatment in both groups. Adverse reactions leading to discontinuation of treatment by the clinician were higher in the isoniazid group $(4.6 \%)$ compared with the rifampicin group $(1.9 \%, \mathrm{p}<0.001)$ and this result was not explained by greater duration of exposure to isoniazid.

This study shows significantly higher adherence to LTBI treatment with a 4 month regime of rifampicin compared with 9 months of isoniazid. Further studies are warranted to look at the efficacy of rifampicin in the treatment of LTBI.

V Nadig

Clinical Fellow, Papworth Hospital, Cambridge, UK; vidya.nadig@papworth.nhs.uk 


\section{Changes to letters in Thorax}

\section{J R Hurst, J A Wedzicha}

\section{Updated guidelines for authors of letters to Thorax}

$\mathrm{H}$ ere at Thorax we believe that letters are the life blood of a journal. Correspondence in response to published articles provides comment and alternative interpretations of data that promote debate, may be unexpected, and add value to the original work. Readers may also take the opportunity to present complementary research findings in such a letter. Moreover, we also publish research letters in Thorax and these are a useful method to present original and important data, or interesting observations that are too limited in scope to require a complete paper. All our letters are cited in PubMed and linked to the original paper.

We wish to encourage you to submit more letters, to join the debate about the work that we publish, and thus to contribute to the vibrancy of our wonderful specialty. To facilitate this we have updated the author guidelines for letters in Thorax. The changes are also an attempt to make our letters page more timely, more up to date and more succinct, which will enable us to publish more of your correspondence. We have previously trialled a feature where "rapid responses" to a published article were posted online. However, we felt that all correspondence about published articles should be submitted for consideration of publication in the full print journal and thus we discontinued the rapid responses feature.

\section{CORRESPONDENCE ABOUT PUBLISHED PAPERS}

For responses to published articles your letter must reach us by the end of the following calendar month (for example, by the end of July for letters referring to articles in the June print issue) and be a maximum length of 400 words, with one figure or table and no more than five references. However, Thorax has an online repository facility so additional information including methodology, data and tables could be placed in the online supplement. You can also get a head start on debating our published papers by viewing accepted work using our Online First facility in which papers are published online in full as soon as they have been accepted for publication. All letters are submitted through our online submission Bench Press system and we always invite the corresponding author of a paper to comment on letters in response to their work. However, as we receive more letters than we can publish, we reject a proportion of letters written in response to published papers. In this case, we always endeavour to supply the authors of a letter with the response received from the original authors.

\section{RESEARCH LETTERS}

For original research letters the maximum length will be 500 words, again with no more than one figure or table and five references. As for correspondence, authors may also make use of the online supplement. All original letters are first seen by one of us, and some of these may be rejected without further review if we feel they do not reach a standard for publication or are not of sufficient interest to the readership of the journal. We send out the remainder of original research letters for further peer review, usually to two reviewers. These letters will then be discussed by the Editors at the regular editorial committee meetings in the same way that we discuss all potentially acceptable papers. However, as with original papers, we also have to reject a significant proportion of the research letters submitted.

Letters pages in the journal are important and help us directly to involve you, our readers. Please keep debates alive in respiratory medicine by writing to Thorax with your comments about the work we have published. This will surely benefit our specialty and stimulate further research.

Thorax 2007;62:474

doi: $10.1136 /$ thx.2007.082685



Authors' affiliations

J R Hurst Letter Editor, Thorax Editorial Office J A Wedzicha Editor-in-Chief, Thorax Editorial Office

Correspondence to: Dr J R Hurst, Thorax Editorial Office, BMJ Publishing Group, London WCIH 9JR, UK

\section{Corrections}

Figure 9 of the article by Sarah R Anderson et al in the February issue of Thorax (Tuberculosis in London: a decade and a half of no decline in tuberculosis epidemiology and control. Thorax 2007;62:162-7) was incorrectly labelled. A corrected version of the figure is available at: $\mathrm{http}$ :// thorax.bmi.com/cgi/content/full/thx.2006.058313/DC1.

Also, the title has been amended and the online version is different to the printed version (revised title: Tuberculosis in London: a decade and a half of no decline).

\section{doi: 10.1136/thx.2006.58313corr}

Appendix 3 of the supplement Pandemic flu: clinical management of patients with an influenzalike illness during an influenza pandemic (Thorax 2007;62(Suppl 1)i1-46) was incorrectly labelled in one part. To the question "Does the patient have pneumonia?" the Yes and No labels on the following arrows were swapped. A corrected version of the figure is available at: http://thorax.bmi.com/cgi/content/full/62/suppl_1/1/DC1

doi: 10.1136/thx.2007.073080corrl 